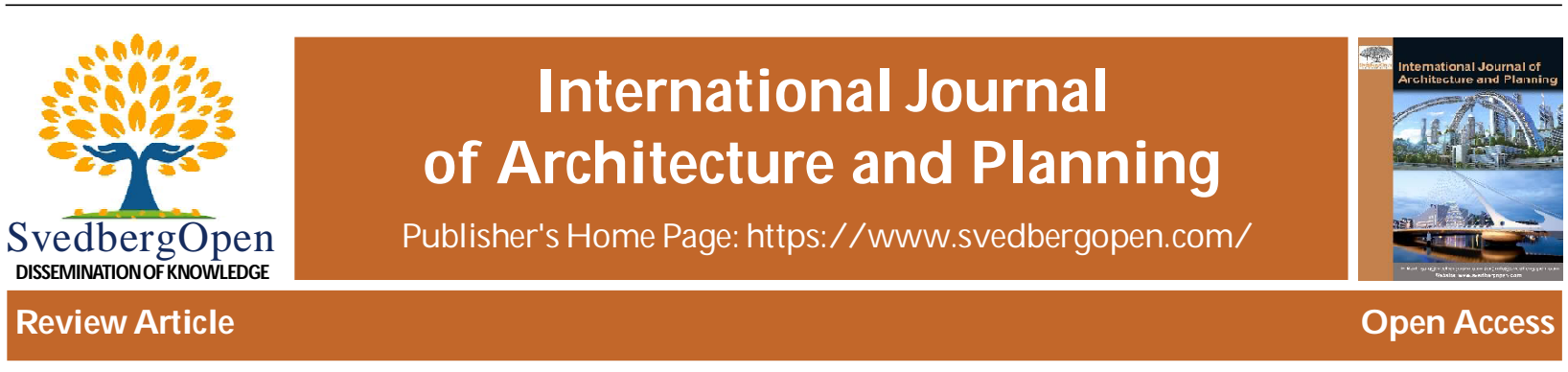

\title{
Housing and Social Capital: A Theoretical Review
}

\author{
Dhammika P. Chandrasekara ${ }^{1 *}$ \\ ${ }^{1}$ Department of Architecture, University of Moratuwa, Moratuwa, Sri Lanka. E-mail: dpcha @uom.lk
}

\section{Article Info}

Volume 1, Issue 2, September 2021

Received : 05 March 2021

Accepted : 19 August 2021

Published : 05 September 2021

doi: 10.51483/IJARP.1.2.2021.1-9

\begin{abstract}
The housing and neighborhood conditions possess the distinct capacity to create or modify the stock of social capital. This is in contrast with the relationship in other domains such as economic development, governance, employment, health and education where social capital acts as the causal agent. The identification of the bonding and bridging sub categories of social capital led to multiple discourses in the field of housing environment. The first group of reviews focuses on the issue of lack of social capital in general and bonding capital in particular and examines the role the physical environment in improving the situation. The second type of investigations stresses the negative effects of bonding capital and the contribution of living environment to enhance such bonds. It argues for the neighborhoods and housing designs to reduce the creation of bonding capital but to encourage the growth of bridging linkages to facilitate socioeconomic progress.
\end{abstract}

Keywords: Bonding social capital, Bridging social capital, Housing, Human settlements, Neighborhood

(C) 2021 Dhammika P. Chandrasekara. This is an open access article under the CC BY license (https://creativecommons.org/licenses/by/4.0/), which permits unrestricted use, distribution, and reproduction in any medium, provided you give appropriate credit to the original author(s) and the source, provide a link to the Creative Commons license, and indicate if changes were made.

\section{Introduction}

The economic capital was considered as the main form of capital until early 1980s. However, the conceptualization of other categories including cultural capital and social capital opened up the discourses on variety of subject areas from different perspectives. Among the different forms of capitals, social capital has drawn the widest attention from researchers in the field of sociology. The current literature points out that social capital is effectively employed by practitioners and researchers in diverse settings. It is argued that economic capital and human capital discourses are evolved mainly within the economic tradition. On the other hand, the social capital is developed in the sphere of sociology but is not limited to it (Akçomak, 2011). The recognition and the popularity of the concept is attributed to its application in broad spectrum of disciplines including health, education, wellbeing, governance, management, political science and economic growth.

The current literature shows that the physical environment of housing and neighborhoods has a direct link to the social capital. The development of the theoretical understandings of social capital has contributed to research studies

\footnotetext{
* Corresponding author: Dhammika P. Chandrasekara, Department of Architecture, University of Moratuwa, Moratuwa, Sri Lanka. E-mail: dpcha@uom.lk
} 
from diverse perspectives. The objective of this paper is to understand the specific characteristics of the relationship between the built environment of human settlements and social capital through the review of the existing literature.

\section{Methodology}

The methodology adopted for the study was the scrutiny of existing academic literature on the area of investigation. Firstly, the concept of social capital and its evolution were examined. The acknowledgement of the existence of different sub categories of social capital demanded in depth analysis in order to understand their varying characteristics.

The patterns of the association between social capital and different disciplines were examined through the review of existing academic writings. A literature search was carried in electronic databases for combination of keywords including social capital, heath, and education, wellbeing, built environment, housing and neighborhood through Boolean operator.

Based on systematic review of the contents of the identified souses of information, the most relevant documents for the investigation were selected leaving out repetitive and less significant studies. Finally, the data from the literature was analyzed to develop the discussion and conclusion.

\section{The Concept of Social Capital}

The social capital is not a recent concept. The old Chinese idea of Guanxi is similar to social capital. John Dewey has employed the term in the first decade of the $20^{\text {th }}$ century. He explained social capital as a positive factor, which is available when individuals connect to others in meaningful ways (Plagens, 2011). Hanifan in 1920 has used the term in his work. Tocqueville has highlighted the contribution of voluntary associations in American democracy in 1966. The argument has been identified as a reference to social capital by later scholars (Putnam et al., 2004). The term 'Social capital' has been independently invented at least six times in the $20^{\text {th }}$ century including, Hanifan, Jane Jacobs, Glen Loury, Ekkehart Schlicht, Pierre Bourdieu and James Coleman (Putnam, 2000).

Bourdieu (1997) described the social capital as, "the aggregate of the actual or potential resources which are linked to possession of a durable network of more or less institutionalized relationships of mutual acquaintance or recognition or in other words, to membership in a group." It provides benefits to the individual due to a membership of a group sharing certain norms. Social capital recognizes the importance of social networks, which not only binds similar people but also connects diverse groups with common values. It creates mutual benefits to the membership. According to Bourdieu (1997), the amount of social capital of an individual depends on the size of the network relations that one can effectively use and the amount of economic and cultural capital that the members of such network possess. Putnam (2000) extended the knowledge and the application of the concept of social capital with the emphasis in the fields of political science and governance. He identified stocks of social capital in community level as well as at national level and resultant effects on development.

The marginalized; both individuals and communities often lack the ability to develop economic and human capital. However, they have opportunities to create social capital (Light, 2004; Zhang et al., 2011). The characteristic could be recognized as a unique feature of the social capital and the main reason for its popularity in sociology related research studies.

\section{Types of Social Capital: Bonding and Bridging Social Capitals}

The development of the theory and its application to empirical studies of diverse contexts revealed that the social capital as one ensemble was not adequate to capture and explain the complex social issues. The early works of Putnam used the single term of 'social capital' to explain the issues of society ranging from informal networks to norms of organizations. The limitation of the approach was highlighted by several scholars (Woolcock,1998; Portes,1998; Woolcock and Narayan, 2000). Subsequently Putnam (2000) recognized two main types of social capital; the bonding social capital and bridging social capital.

The need to move out from the 'all encompassing' big tent was emphasized while recognizing that there are various categories of social capital, which create different consequential results. It was further stated that all such effects are not necessarily positive (Putnam et al., 2004) the identification of different types of social capital made significant impact on the development of the theory. It made clarity in explanation and allowed application to varying empirical studies. 


\subsection{Bonding Social Capital}

This is the common type of social capital and as a result, it is generally mentioned without the 'bonding' prefix. The social capital among the horizontal layers of the social groups is recognized as the bonding capital. It is the connections of the members of similar nature groups. It strengthens the identities of homogeneous communities.

"Bonding social capital is good for undergirding specific reciprocity and mobilizing solidarity. Dense networks in ethnic enclaves, for example provide crucial social and psychological support for less fortunate members of the community, while furnishing start-up financing, markets and reliable labor for local entrepreneurs" (Putnam, 2008).

Vidal (2004) argues that the bonding social capital brings people closer who know each other. The bonding capital is essentially required for the poor, which makes significant contribution for their survival in difficult situations. The bonding social capital operates at a local level. It helps to create empowerment and multi-functional strong ties among horizontal networks. The mutual assistance is restricted to members of the network and is not extended outside groups (Macke and Dilly, 2010).

Bonding capital assists the marginalized of the community in different ways for their social, as well as economic activities. However, it mainly concentrates on daily lives and survival issues particularly of the poor. "Consequently, social networks consisting of kin and friends often are considered as bonding capital, which is argued to provide people in the group with emotional and material supports for getting by in their daily lives" (Zhang et al., 2011).

The bonding social capital could lead to negative effects as well. The strong bonds among the similar members do not always create positive results. The closer ties especially among people of the low income and ethnic minorities lead to isolation and segregation of them from the mainstream social systems.

Woolcock (1998) argues that the bonding capital facilitates the start of a new economic activity by an immigrant but it also restricts the development of the business. The strong obligations and connections to the immigrant community prevent opening up of the enterprise to a larger heterogeneous networks. Furthermore, high level of social solidarity does not guarantee economic development. The examples from underdeveloped world such as Kenya, Hati, Ruwanda and Latin American countries confirm the argument that the high level of local bonding has failed to raise the living conditions of marginalized (Woolcock and Narayan, 2000).

Portes (1998) presents a comprehensive analysis on the different types of negative impacts of the social capital. He describes four types of negative consequences of social capital. Although he does not use the term, it is clear that he is referring to the bonding social capital in this regard. The first two effects are related to the economic sphere. Bonding capital could prevent outsiders entering into an economic activity controlled by a closely knit community. Conversely the group or community closure could also contribute to the failure of business due the strong obligations to fellow members who demands jobs, loans and financial assistance. The last two negative consequences are connected to the sociability. The need for the respect to the norms of the group could restrict the freedom at family and individual levels. Finally group conformity would create anti mainstream social systems leading mafias, prostitution, gambling rings and youth gangs.

\subsection{Bridging Social Capital}

The social relations among the vertical layers of the society or people of different socio economic backgrounds are described as the bridging capital. In contrast to inward looking bonding capital, the bridging capital is outward looking. Briggs (1997) differentiates the characteristics of bonding capital from the bridging capital without employing the specific terminology. He recognizes the former as to 'get by' and the latter to 'get ahead'. "The first is to 'get by' (for social support), that is, to cope with the everyday challenges that life presents, from flat tires to divorces........ The second use for social capital is to 'get ahead'. Social capital is used for social leverage, that is, to change or improve our life circumstances or opportunity set." He explains that the disadvantaged poor people can do very little to improve the quality of life of similar persons. Instead, the social capital coming from the members of higher social strata would be more beneficial.

Putnam (2008) credits Ross Gittell and Avis Vidal for the introduction of the terms of bonding and bridging in to the field of social capital. Putnam quoting the sociologist Mark Granovetter's writings in 1973 explains that the weak ties with the distant associates are more important than the strong ties with the inner circle in searching for jobs. Without using the term social capital, Granovetter (1973) explains the mechanisms of the establishment and significant roles of the bridging social networks at micro level. 
Zhang et al. (2011) through an empirical study show that a strong correlation exists between the bridging capital and economic growth. It is explained that the bonding capital does not show such an effect. Bridging social capital consists of weak or thin vertical connections. In contrast, the bonding capital is consisted of thick horizontal connections. The bridging capital offers opportunities for economic advancement. The information that could not be found among the neighborhoods or community is communicated through the bridging capital. "While bonding social capital brings together people of similar social locations, bridging social capital provides access to different kinds of people, which in turn provide access to different kinds of information and resources" (Johnson et al., 2011).

The bridging capital is more effective for economic advancement of people while the bonding would contribute during the emergencies or to sustain the routine requirements (Derose, 2008). Nevertheless, the thin and thick ties are not always synonymous with bonding and bridging capitals. Certain studies show the existence as well as the benefits of loose ties in bonding and strong ties in bridging capitals (Leonard and Onyx, 2003).

\section{Social Capital as a Causality}

The concept of social capital has been widely used in scholarly works in different fields. Most of the studies focus the attention to investigate the cause and the effect relationship. Social capital has been recognized as a significant causality of diverse disciplines including economic development, governance, employment, health and education (Putnam, 2000; Coleman, 1988; Fukuyama, 2001; Woolcock, 1998). It is argued that high level of social capital contributes to positive effects in the fields described above. Hence the attention is on the role of social capital as a generator of change in other disciplines.

The relationship is similar to that of the other forms of capitals such as economic capital and cultural capital, which are considered as assets or resources contributing to human development. For example social capital has been recognized as a strong contributory factor affecting the conditions of health. It is explained that social capital contributes to improve both physical and mental health conditions (Scheffler and Brown, 2008; Kawachi et al., 1997).

Similarly it is shown that the social capital makes positive contribution to employment and economic growth at micro or family level (Putnam, 2008; Briggs, 1997) as well as at macro or the regional or national level (Woolcock, 1998). The research studies (Zhang et al., 2011; Sabatini, 2008) have recognized the varying effects of bonding and bridging social capitals on the employment and economic wellbeing. It is elucidated that the bonding capital or the horizontal homogeneous connections contribute to sustain the economic conditions of the marginalized. It would not facilitate the access to the higher paid or high status jobs for the unprivileged. On the other hand bonding capital of the privileged or the elite groups would assist to continue the status quo.

The bridging social capital is seen as a facilitator for finding better employments. It provides access to information, which is not found within the horizontal connections. Lancee (2012) shows that links between the natives and the immigrants in Germany contribute positively for the employment and the occupational status of the latter group. The coethnic and family based social capital offers resources to find a job only during the initial period after the arrival of immigrants. It does not make an impact on the occupational status.

It has also been explained that social capital contributes positively to the development of human capital (Coleman, 1988; Tedin and Weiher, 2011; Teachman et al., 1997). It is shown that the social capital of the family plays a key role in educational attainments of a child. Coleman (1988) identified the reasons for better performances of Asian children over their peers in American schools. He found that the Asian parents even with low level of human capital buy a second copy of text books for themselves to study and contribute for the education of the child. The financial and human capitals of parents are important determinants of the process of education of a child (Teachman et al., 1997). However, Coleman (1988) highlighted the significance of parental social capital for the child's educational growth.

Putnam identifies stock of social capital in community level as well as at national level and resultant effects on development. He explains the impact of the social capital of community groups with examples of regional variations from north and south Italy (Portes, 2000; Woolcock, 1998). Putnam (2000) explains the declining social capital in the American society and the negative consequences especially leading to poor governance.

The causal effects of social capital is extended to many other areas. It makes positive impacts on diverse fields such as in agriculture developments (Rivera et al., 2018), mitigation of crimes (Carcach and Huntley, 2002) and environmental protection (Anderson et al., 2002). 
It is explained that under certain situations, education (Heyneman, 1998; Alesina and Ferrara, 2002) and health (Scheffler and Brown, 2008), act as agents of developing social capital. Nevertheless the main pattern of relationships is that social capital plays the vital role as the causal factor making effects in other disciplines discussed above.

\section{The Distinctive Relationship Between Social Capital and Housing Environment}

The association between the built environment of housing and social capital has been dealt extensively. However, the main focus of the discourse is on the effects of the built environment on the creation of the social capital. This is completely different to the studies of the other disciplines where the main attention is on the impact of social capital as a causal agent. In contrast, the neighborhoods and housing act as an important influencing factor in creating social capital.

The distinct capability of the physical environment of housing and neighborhood to generate social capital has drawn the attention of academic studies. The investigations could be categorized in to two types. The first group focuses on the issue of lack of social capital in general, examining how the design and planning of the physical environment could improve the situation. The second type of studies, recognizing the variations of social capital, highlights the negative effects of bonding capital and the contribution of physical environment to enhance such bonds. It discusses the bridging capital as a positive factor and the strategies in the design of residential environment to facilitate such linkages.

\subsection{The Discourse on the Development of (Bonding) Social Capital Through Neighborhood and Housing Designs}

The decline of interactions among people in general and among the urban middle class in particular started to demand for stronger social capital. The built environment was identified as one of the key and effective influencing factors to realize this end. The significance of neighborhoods in creation of social capital and interactions has been highlighted by several studies (Forrest and Kearns, 2001; Humphreys,2007; Flint and Kearns, 2006). It is shown that the trust and the attachments created by the neighborhoods contribute to the actions of participation (Dekker, 2007).

One of the pioneering scholars to use the term social capital is Jacobs (1961), in her famous book 'The Death and Life of Great American Cities'. She argued that the social networks at neighborhood level act as self-government creating active and secure habitats for people. She further stressed the modern planned cities do not facilitate such social networks thus leads to a natural death. The confusion of the use of term to describe social connections as well as the economic capital by Hanifan in earlier works has credited Jacobs for the authorship of the concept among the modern writers (Light, 2004).

"If self-government in the place is to work, underlying any float of population must be a continuity of people who have forged neighborhood networks. These networks are a city's irreplaceable social capital. Whenever the capital is lost, from whatever cause, the income from it disappears, never to return until and unless new capital is slowly and chancily accumulated" (Jacobs, 1961).

Jacobs recognized several factors, which contribute to enhance the social capital. Sidewalks, mixed uses, diverse of activities, high human densities were identified as the key ingredients for enhanced human interaction at neighborhood level. Jacobs did not distinguish between bonding and bridging capitals. She was critical on modern architecture and urban planning which had destroyed the social links among the members of the community. She explained declining social capital at locality level as the main reason for the death of American cities. Nevertheless, it could be argued that she indirectly advocated heterogeneous social systems in recommending diversity as an essential constituent in urban design.

Since the emergence of the concept, a substantial volume of research works has attempted to investigate the design aspects of housing and neighborhoods, which contribute to the development of social capital. The research works do not attempt to distinguish between the bonding and bridging capitals. However, the emphasis of the inquiries is on the bonding capital, thus fall in to the first type of studies. Walkability, Visibility, Diversity in activities, clustered residential neighborhoods and public activity spaces could be recognized as more important design elements of built environment that contribute to the development of social capital.

Spatial design that facilitates walkability has been described as a key element that strengthens human interactions. Speck (2012) and Gehl (2010) are strong advocates for prominence to pedestrians over motor vehicles due to many reasons including enhancing the liveliness of the city by encouraging human interaction. 
Visibility of fellow humans and their actions encourage social dialogue. The spatial designs encouraging ground level activities, (Jacobs, 1961) and front porches (Moobela et al., 2009) facilitate visibility in built environment. The term 'eyes on street' is used by Brown and Lombard (2014) to discuss the issue in reference to the linkages resulting from the openings on the facades and semi open spaces in residential buildings facing the public spaces.

The diversity of activities as opposed to zoning, contributes to the liveliness of a place during most of the time periods of the day (Jacobs, 1961) (Mazumdar et al., 2017). On the contrary, the zoning of functions would make urban areas dead during certain time periods of the day and decrease the possibilities of social interactions. The public spaces within housing neighborhoods encourage frequent encounters of residents. Jacobs (1961) advocated integrating parks, squares and public buildings into residential districts to ensure the liveliness throughout the day. Campos-Vazquez and Cuilty (2014) show that building of social capital is a time consuming process to which the public spaces contribute positively.

Remarkably the clustered residential arrangements, which clearly enhance interactions among the residents, are not discussed by scholars as a key strategy in developing social capital. However clustering facilitates sharing of common spaces, face-to-face meetings and more importantly a strong sense of neighborhood among the residents.

\subsection{The Discourse on the Development of Negative Bonding Social Capital and Positive Bridging Social Capital Through Neighborhood And Housing Design}

The negative effects of bonding capital have been the main theme for the second type of research studies. The emergence of the concepts of bonding and bridging social capitals allowed analyzing and theorizing the effects more clearly. The neighborhoods of low income and marginalized communities make stronger connections among the similar people while preventing them associating with the external communities (Humphreys, 2007).

Even prior to the advent of the idea of bonding and bridging capitals, Wilson (1987) in his seminal work; 'The truly Disadvantaged' analyzed the concern with reference to the American cities and strengthened the argument of undesirable neighborhood effects on community behavior. The moving out of the educated middle class from the inner cities made such neighborhoods, residential areas of the poor and the less fortunate ethnic minorities. The physical segregation caused social isolation of the inner city communities, which led to the development of ghetto mentality. The stronger bonds among the inhabitants of such settlements resulted in deviance behavior such as crimes, school dropouts and single parents.

The regulatory frameworks and legal actions that prevent the development of homogeneous social group enclaves could be recognized as strategies adopted to avoid the neighborhood influence on the formation of negative social capital. Such approaches are aimed to deter the segregation of neighborhoods of communities in terms of ethnicity, income, religion. The group specific settlements or the enclaves develop the bonding social capital. The blend of heterogeneous groups in neighborhoods facilitates to enhance the positive bridging social capital. The housing policy of Singapore government insists a mix of families of different ethnicities in social housing blocks. The understanding of undesirable effects of ethnic enclaves has given rise to such a policy in allocation of residential units (Phang, 2007). The landmark judgment of city of Yonkers in New York directed the town authorities to construct public houses for nonwhites in the area, which is a white enclave (Briggs, 1998). Such bonding social capital formations are mainly determined by the living environment. Flint and Kearns (2006) explain the neighborhoods of the disadvantaged as one of the main causes for low level of bridging social capital.

Curley (2005) argues that heterogeneous neighborhoods possess not only greater human capital but also high level of social capital. The homogeneous communities lacking in bridging social capital propagates poverty, welfare and crime. Curley explains that the social networks and capital in the poor neighborhoods are limited to the social support with strong ties among themselves. But they do not have connections to external world, which affect the upward social mobility. Curley shows that the parental practices, children influenced by adult role models, peer influences on children contribute to the social isolation of the younger generation in poor neighborhoods. The 'HOPE VI' housing program implemented in USA in 1993 has taken into consideration the negative effects of segregation of marginalized into separate housing areas. The attempts to house the excluded families through relocation projects and the financial assistance in the form of vouchers have provided opportunities for better social mix and positive results in reducing poverty levels (Curley, 2005).

The Moral Underclass Discourse (MUD) argues in the same direction emphasizing the negative effects created by subsidized social housing due to segregation of marginalized communities (Levitas, 2005). The neighborhood and housing effects mainly create social groups lacking of morals and values which in turn leads to social exclusion. 
It is not only the poor neighborhoods that are recognized as anti-social physical environments but also the segregated housing of the elite. The housing settlements of gated communities are planned purposely to avoid any interactions with the rest of people in the locality. Such environments strongly resist the development of bridging social capital with the surrounding neighborhood (Blandy and Lister, 2005). It is argued that the mixed activity physical environments contribute to the increase of bridging social capital. The face to face meetings strongly support the social understanding and cohesion. The multi-functional centers with diverse activities such as gathering places, educational spaces encourage such interactions thus the bridging social capital (Svendsen, 2010).

\section{Conclusion}

The scrutiny of the existing literature points out the significance of built environment of human settlements on social capital. The housing and neighborhood designs possess the distinct capability to generate social capital. This is in contrast to the relationship in many other fields where social capital acts as the causality. Furthermore, the housing and neighborhoods have a direct impact in altering the stock of different types of social capital such as bonding and bridging.

The negative effects of bonding social capital have been strongly explained especially in relevance to the low income and marginalized groups. Their residential environments create strong sense of territoriality and identity for the community. The resultant segregation acts as a negative factor for socio and economic progress. Consequently, social housing has been identified as a cause for the poverty and exclusion (Arthurson and Jacobs, 2004).

Nevertheless the significance of bonding capital on social sustainability cannot be ignored, despite of its undesirable effects. When the built environment does not facilitate social interactions, the wellbeing and quality of life of the residents weaken. For the marginalized, bonding capital is essential for the survival or to 'get by'. As Jacobs (1961) explains, the urban design and architecture of modern movement have made sterile social environments especially in middle income neighborhoods. In crisis situations of disasters the community social capital becomes a valuable asset for resilience and re building.

On the contrary, the weak links of bridging capital influence socio- economic advancement of the poor. The design of the neighborhood and housing could reduce the creation of bonding capital while encouraging the growth of bridging linkages. The application is not only relevant for the settlements of the poor but also for the socially segregated ethnic and religious enclaves. The varying effects of bonding and bridging capitals are not only important to global south where poverty is a main issue. In the developed global north, the design of residential areas aimed at improving the bridging social capital has become vital in addressing the problem of social exclusion, mainly created due to immigrant citizenship.

The understanding of the impact of the built environment on social capital leads to positive applications in housing practice. It is vital to design human settlements encouraging the desired balance between bonding and bridging capitals, thus ensuring the survival with the cooperation from similar people while providing opportunities for positive transformations facilitated by heterogeneous linkages.

\section{References}

Akçomak, I.S. (2011). Social Capital of Social Capital Researchers. Review of Economics and Institutions, 2(2),5.

Alesina, Alberto and Ferrara, Eliana (2002). Who Trusts Others?. Journal of Public Economics, 85(2), $207-234$.

Anderson, C. Leigh, Laura Locker, and Rachel Nugent. (2002). Microcredit, Social Capital, and Common Pool Resources. World Development, 30, 95-105.

Arthurson, K. and Jacobs,,K. (2004). A Critique of the Concept of Social Exclusion and its Utility for Australian Social Housing Policy, Australian Journal of Social Issues, 39(1), 25-40.

Blandy, S. and Lister, D. (2005). Gated Communities: (Ne) Gating Community Development?. Housing Studies, 20(2), 287-301.

Bourdieu, P. (1997). The Forms of Capital, in Education Culture, Economy, Society. eds A.H. Halsey, H. Lauder, P. Brown and S.A.Stuart Wells, Oxford: Oxford University Press,.46-58.

Briggs, Xavier de Souza, (1997). Social Capital and the Cities: Advice to Change Agents. National Civic Review, 86(2), 111-117. 
Briggs, Xavier de Souza. (1998). Brown Kids in White Suburbs: Housing Mobility and the Many Faces of Social Capital. Housing Policy Debate, 9(1), 177-221.

Brown, S. C. and Lombard. (2014). Neighborhoods and social interaction’, in R.Cooper, E. Burton and C. L. Cooper (Eds.), Wellbeing and the Environment: Wellbeing: A Complete Reference Guide, Volume I,. West Sussex, UK: John Wiley \& Sons, Ltd, 91-118.

Campos-Vazquez, R.M. and Cuilty, E. ( 2014). Do investments in public spaces generate social capital? Evidence for Mexico, Well-being and Social Policy, 9 (1), 123-155.

Carcach, C. and Huntley, C. (2002). Community Participation and Regional Crime. Trends and Issues in Crime and Criminal Justice, no.222 Australian Institute of Criminology, Canberra.

Coleman, James S. (1988). Social Capital in the creation of Human Capital. The American Journal of Sociology, 94 Supplement, S 95-S 120.

Curley, A.M. (2005). Theories of Urban Poverty and Implications for Public Housing Policy. Journal of Sociology and Social Welfare, XXXII, 97-119

Dekker, K. (2007). Social Capital, Neighbourhood Attachment and Participation in Distressed Urban Areas. A Case Study in The Hague and Utrecht, the Netherlands. Housing Studies, 22(3), 355-379

Derose, K.P. (2008). Do Bonding, Bridging, and Linking Social Capital Affect Preventable Hospitalizations?. Health Services Research, 43(5) Part I, 1520-1541.

Flint, J. and Kearns, A. (2006). Housing, Neighbourhood Renewal and Social Capital: The Case of Registered Social Landlords in Scotland. European Journal of Housing Policy, 6(1), 31-54.

Forrest, R. and Kearns A. (2001). Social cohesion, Social capital and the Neighbourhood, Urban Studies, 38(12), 21252143.

Fukuyama, F. (2001). Social Capital, Civil Society and Development. Third World Quarterly, 22, 7-20.

Gehl, J. (2010). Cities for People, Island Press, Washington.

Granovetter, M.S. (1973). The Strength of Weak Ties. The American Journal of Sociology, 78(6), 1360-1380.

Heyneman, S.P. (1998). The Transition from Party/State to Open Democracy: The Role of Education. International Journal of Educational Development, 18(1), 21-40.

Humphreys, E. (2007). Social capital in disadvantaged neighbourhoods: A diversion from needs or a real contribution to the debate on area-based regeneration?. Irish Journal of Sociology, 16 (20) 50-76.

Jacobs, Jane. (1961). The Death and Life of Great American Cities, Random House, New York.

Johnson J.A., Honnold J. and Threlfall P. (2011). Impact of Social Capital on Employment and Marriage among Low Income Single Mothers. Journal of Sociology \& Social Welfare, XXXVIII (4), 09-31.

Kawachi, I., Kennedy, B.P. , Lochner, K. and Prothrow-Stith, D. (1997). Social Capital, Income Inequality, and Mortality. American Journal of Public Health, 87(9), 1491-1498.

Lancee B. (2012). The Economic returns of bonding and bridging social capital for immigrant men in Germany. Ethnic and Racial Studies, 35(4), 664-683.

Leonard, R. and Onyx, J. (2003). Networking Through Loose and Strong Ties: An Australian Qualitative Study. Voluntas: International Journal of Voluntary and Nonprofit Organizations, 14(2), 189-203.

Levitas, R. (2005). The Inclusive Society? Social Exclusion and New Labour, Palgrave Macmillan, Basingstoke.

Light, Ivan. (2004). Social Capital's Unique Accessibility. Journal of The American Planning Association, 70(2), 145151.

Macke, J. and Dilly E.K. (2010). Social Capital Dimensions in Collaborative Networks: The Role of Linking Social Capital. International Journal of Social Inquiry, 3(2), 121-136.

Mazumdar, S., Learnihan, V., Cochrane, T. and Davey, R. (2017). The Built Environment and Social Capital: A Systematic Review. Environment and Behavior, 50(2), 119-58.

Moobela, C., Price, A., Mathur, V. and Paranagamage, P. (2009). Investigating the Physical Determinants of Social Capital and Their Implications for Sustainable Urban Development. The International Journal of Environmental, Cultural, Economic Sustainability, 5(2), 255-270. 
Phang, Sock Yong. (2007). The Singapore Model of Housing and the Welfare State. Housing and the New Welfare State: Perspectives from East Asia and Europe. 15-44. Research Collection School of Economics, Singapore Management University.

Plagens, Gregory, K. (2011). Social Capital and Education: Implications for Student and School Performance. Education \& Culture, 27(1), 40-64.

Portes, Alejandro. (1998). Social Capital: Its Origins and Applications in Modern Sociology. Annual Review of Sociology, 24, 1-24.

Portes, Alejandro. (2000). Two Meanings of Social Capital. Sociological Forum, 15(1), 1-12.

Putnam, Robert. (2000). Bowling Alone: The Collapse and Revival of American Community, Simon \& Schuster Paperbacks, New York.

Putnam, Robert. (2008). Thinking about Social Change in America. Social exclusion-Critical Concepts in Sociology Vol.IV, eds. Byrne David, Routledge, New York, 66-82.

Putnam, Robert., Light, Ivan., Briggs, Xavier de Souza., Rohe, William., Vidal, Avis., Hutchinson, Judy., Gress, Jennifer and Woolcock M. (2004). Using Social Capital to Help Integrate Planning Theory, Research, and Practice. Journal of The American Planning Association, 70(2), 142-192.

Rivera, M., Knickel, K., Díaz-Puente, J.M. and Afonso, A. (2018). The role of social capital in agricultural and rural development: Lessons learnt from case studies in seven countries. Sociologia Ruralis, 59(1), 66-91.

Sabatini, F. (2008). Social Capital and the Quality of Economic Development. Kyklos, 61(3), 466-499.

Scheffler, R.M. and Brown, T.T. (2008). Social Capital Economics and Health: New Evidence. Health Economics, Policy and Law, 3(4), 321-331.

Speck, J. (2012). Walkable City: How Downtown Can Save America, One Step at a Time, Farrar, Straus and Giroux, New York.

Svendsen, G.L.H (2010). Socio-spatial Planning in the Creation of Bridging Social Capital: The Importance of Multifunctional Centers for Intergroup Networks and Integration. International Journal of Social Inquiry, 3 (2), 45-73.

Teachman, J.D., Paasch, K. and Carver, K. (1997). Social Capital and the Generation of Human Capital. Social Forces, 75(4), 1343-1359.

Tedin, K.L. and Weiher, G.R. (2011). General Social Capital, Education-Related Social Capital, and Choosing Charter Schools. Policy Studies Journal, 39(4), 609-629.

Vidal, A.C. (2004). Building Social Capital to promote Community Equity. Journal of The American Planning Association, 70(2), 164-168.

Wilson, W.J. (1987). The Truly Disadvantaged The Inner City, the Underclass, and Public Policy, University of Chicago Press.

Woolcock, M. (1998). Social Capital and Economic Development: Towards Theoretical Synthesis and Policy Framework, Theory and Society, 27,151-208.

Woolcock, M. and Narayan, D. (2000). Social Capital: Implications for Development Theory, Research, and Policy. World Bank Research Observer, 15(2), 225-250.

Zhang, S., Anderson, S.G. and Zhan, M. (2011). The Differentiated Impact of Bridging and Bonding Social Capital on Economic Well-Being: An Individual Level Perspective. Journal of Sociology \& Social Welfare, XXXVIII (1), $119-142$.

Cite this article as: Dhammika P. Chandrasekara (2021). Housing and Social Capital: A Theoretical Review. International J ournal of A rchitectureand Planning. 1(2), 1-9. doi: 10.51483/ IJA RP.1.2.2021.1-9. 